\title{
Nonalcoholic Wernicke's Encephalopathy with Prominent Astasia and Optic Neuropathy
}

\author{
M. Gokce $\quad$ E. Bulbuloglu ${ }^{\mathrm{b}} \quad$ D. Tuncel ${ }^{\mathrm{a}} \quad$ G. Ozdemir $^{\mathrm{c}} \quad$ I.T. Kale ${ }^{\mathrm{b}}$ \\ Departments of a Neurology, ${ }^{b}$ General Surgery and ${ }^{c}$ Ophthalmology, Medical School, \\ University of Kahramanmaras Sutcu Imam, Kahramanmaras, Turkey
}

\section{Key Words}

Wernicke's encephalopathy - Thiamine deficiency · Gastrointestinal surgery · Astasia - Optic neuropathy

\begin{abstract}
Objective: To present a case with nonalcoholic Wernicke's encephalopathy (WE) developing astasia and optic neuropathy as major sequelae. Clinical Presentation and Intervention: A 47-year-old woman developed WE following operation for pyloric stenosis. She received total parenteral nutrition before and after operation, but on the second postoperative day she developed visual hallucination and confusion, followed by nystagmus, ophthalmoplegia, apathy, dysarthria and coma. Although the patient has recovered with thiamine treatment, astasia and optic neuropathy persisted as major morbidities. Conclusion: The report shows that astasia and optic neuropathy may be prominent sequelae in some patients with WE.
\end{abstract}

\section{Introduction}

Wernicke's encephalopathy (WE) is characterized by nystagmus, abducens and conjugate gaze palsies, gait ataxia and mental confusion. It is most commonly encountered in patients with a history of chronic alcoholism; however, it is primarily a nutritional disorder [1]. It has also been reported in nonalcoholic patients with conditions such as anorexia nervosa, stomach cancer, Crohn's disease, hemodialysis, intestinal surgery, total parenteral nutrition (TPN) and poor oral intake [2-6].

WE has a high mortality and morbidity if treatment is delayed. Optic neuropathy in nonalcoholic WE has been published in a few cases [7, 8]. Astasia, difficulty in sitting, standing and walking related to thalamic lesions, has not been reported in association with WE. Here, we describe a case with WE following gastrointestinal surgery who developed prominent astasia and optic neuropathy.

\section{Case Report}

Following general surgery, a 47-year-old woman was admitted to the Intensive Care Unit (ICU) with nausea, vomiting, pain and distension of the epigastrium. Twelve years ago, she underwent truncal vagotomy and gastroenterostomy for pyloric stenosis. After

$\begin{array}{ll}\text { KARGER } & \text { ( ) 2005 S. Karger AG, Basel } \\ \text { Fax +4161306 1234 } 34-7571 / 05 / 0146-0438 \$ 22.00 / 0 \\ \begin{array}{l}\text { E-Mail karger@karger.ch } \\ \text { www.karger.com }\end{array} & \begin{array}{l}\text { Accessible online at: } \\ \text { www.karger.com/mpp }\end{array}\end{array}$

Dr. Mustafa Gokce

Tip Fakultesi. Noroloji A.D., Kahramanmaras Sutcu Imam Universitesi TR-46050 Kahramanmaras (Turkey)

Tel. +90 344 2212337, ext. 245/368, Fax +90 3442212371

E-Mailhmgokce@ksu.edu.tr 

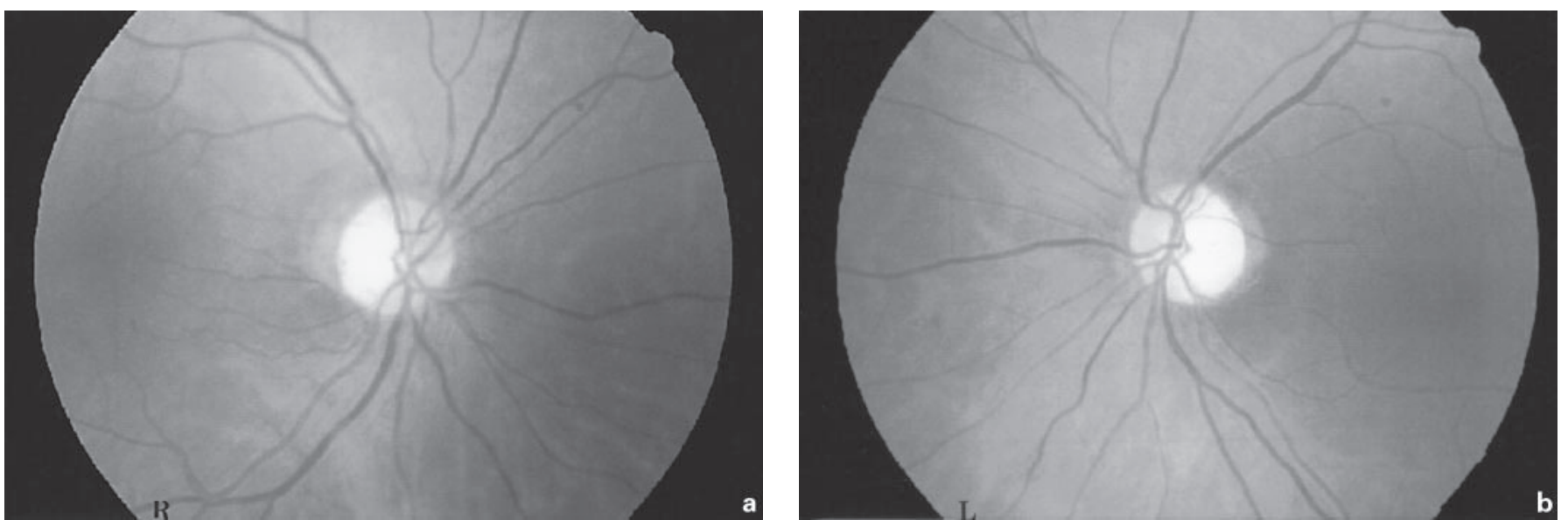

Fig. 1. Bilateral optic disc pallor after WE lasting 1 year: left optic disc (b) is paler than right (a).

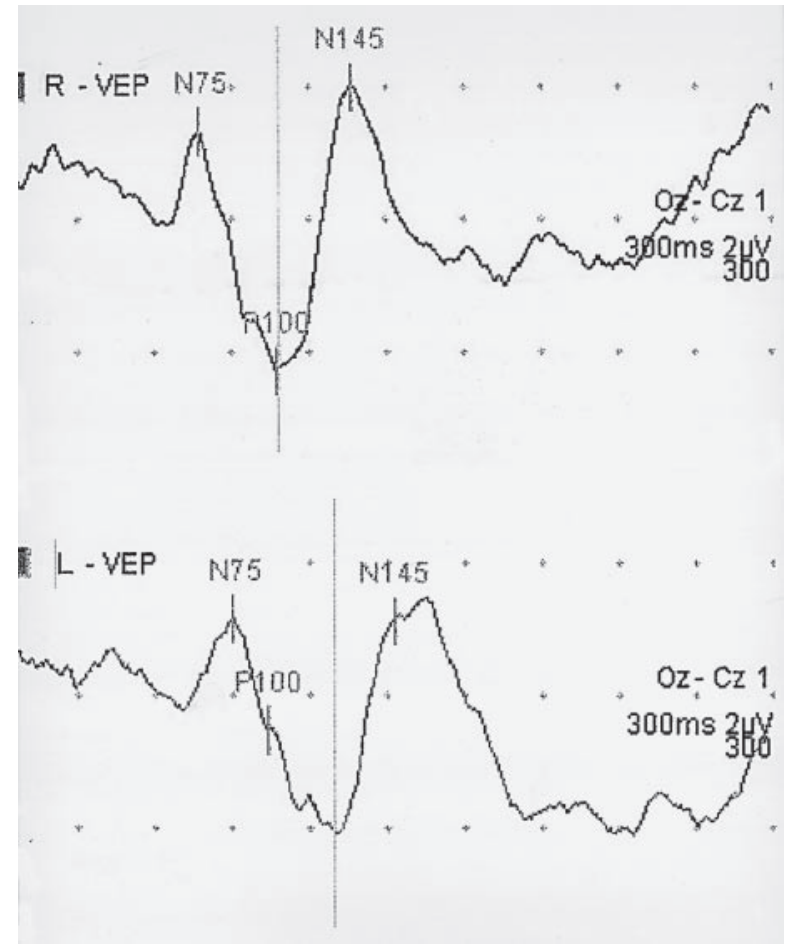

Fig. 2. The patient's visual evoked potentials: $P 100$ latencies are longer on the left $(\mathrm{P} 100=129 \mathrm{~ms})$ than on the right which is nearly normal $(\mathrm{P} 100=108 \mathrm{~ms})$.

the surgery, she was relatively well but vomited sometimes and lost $20 \mathrm{~kg}$ during last year. She had never used alcohol and tobacco. Abdominal distension was seen on physical examination. Routine laboratory examinations were normal. TPN was started, and on the 13 th day subtotal gastrectomy with Roux-en-Y surgery was performed for obstruction due to the bridge at the efferent loop. She was recovering, and TPN was resumed on the first postoperative day but she developed visual hallucination on the 2 nd postoperative day followed by a mild confusion in the same night without any identifiable metabolic cause; neurological examination was almost normal. On the 3rd postoperative day, the patient deteriorated clinically with apathy, isochoric sluggish pupils, mild dysarthria and suspected horizontal nystagmus. Contrast and noncontrast computerized tomography scans of the head were normal. On the 4th postoperative day, bilateral horizontal nystagmus in the primary position of the eyes and bilateral 6th cranial nerve palsy but more prominent on the right eye, and bilateral optic disc infiltration with hazy borders, though more so in the left eye, were seen. Cerebrospinal fluid examination showed high protein content (99 $\mathrm{mg} / \mathrm{dl}$, range: $15-45)$. During the 5th postoperative day her consciousness gradually decreased and she became comatose on the 6 th day. Thiamine deficiency was suspected. Thiamine in combined vitamin formulation was started since pure thiamine formulation was not available. The patient gained consciousness on the same day and was moved from the ICU to the ward on the 3rd day of the treatment.

After regaining consciousness, she complained of decreased visual acuity and could not sit up in bed or stand. Bilateral optic disc edema and slight hyperemia with hazy borders of the disc and profound visual loss were seen on detailed ophthalmological examination. She could stand up with the help of two people on the 15th postoperative day. Brain and orbital MRI performed on the 20th postoperative day were normal. The patient was discharged with mild apathy, amnesia, difficulty in walking and bilateral optic disc pallor prominent on the left. Her visual acuity improved with time. At the first postoperative month, she had a corrected visual acuity of 0.5 in the right eye and 0.3 in the left eye, as per Snellen chart. The light reflex was almost normal. In the first postoperative year, ophthalmologic examination showed bilateral optic disc pallor, prominent on the left (fig. 1) and a corrected visual acuity of 0.6 in the right eye and 0.4 in the left eye. A prolonged P100 wave on the left eye (P100: $129 \mathrm{~ms}$ ) and nearly normal P100 wave on the right eye (P100: $108 \mathrm{~ms}$ ) were seen in visually evoked potentials (fig. 2). At the end of the first year she was able to walk a few steps without help. 


\section{Discussion}

Our patient developed WE probably due to impaired thiamine absorption because of the previous gastrointestinal surgery, loss of thiamine due to vomiting, increased utilization of thiamine due to parenteral glucose administration, and the administration of vitamin-free supplement in the pre- and postoperative periods.

The two main problems observed during the recovery period were decreased visual acuity and difficulty in sitting or standing up. She could hardly stand up in the 2 nd postoperative week. After 3 months, she was able to walk a few steps without help. This remained almost the same in the first year. The condition could not be explained on the basis of sensory or cerebellar dysfunction since there was an absence of obvious sensory (pinprick, light touch, deep, vibration) and cerebellar dysfunction. However, the Romberg test and deep tendon reflexes were almost normal. Also, the patient's sitting and standing difficulties could not be explained. Truncal ataxia usually indicates midline cerebellar disease. In our opinion, this was more appropriately a case of astasia.

The term astasia-abasia has been used for hysterical gait, but this terminology denotes inability to stand and walk [9]. Astasia due to cerebrovascular diseases and tumor with unilateral thalamic lesions was first described by Masdeu and Gorelick [10]. The disturbance differed from cerebellar ataxia, in that gait was not broad based or lurching. We could not find any astasia due to WE in the literature. The thalamus, hypothalamus, floor of the fourth ventricle and mamillary bodies are involved in WE. It can be shown either histopathologically [11] or by MRI in the acute stage [12]. Although our patient's brain and orbital MRI on the 20th day were normal, we think that astasia may be associated with the involvement of the thalamus or its connections. Although Masdeu and Gorelick [10] suggest that astasia is transient, with resolution within days or weeks, it persisted in our patient. The differences may arise from etiopathological variation.

The second major problem of the patient was decreased visual acuity. Ocular manifestations of WE generally include nystagmus, ophthalmoplegia and very rarely visual deterioration and optic neuropathy. We found only two cases of optic neuropathy in nonalcoholic patients in the literature $[7,8]$. Both cases had thiamine deficiency induced by parenteral nutrition. Similar to our case, Van Noort et al. [7] reported total visual loss with partial recovery after thiamine supplementation in WE. Sometimes, in WE visual acuity may also be normal despite optic neuropathy [8].

\section{Conclusion}

This case report shows WE should be suspected in a patient receiving TPN in an ICU with nonspecific symptoms such as visual hallucination or confusion. In such instances vitamin supplementation is beneficial. Although rare, optic neuropathy and astasia may be the main sequela in nonalcholic patients with WE.

\section{References}

1 Victor M, Ropper AH: Adams and Victor's Principles of Neurology, ed 7. McGraw-Hill, 2001, pp 1205-1232.

2 Perkin GD, Lyon IM: Neurology and the gastrointestinal system. J Neurol Neurosurg Psychiatry 1998;65:291-300.

- 3 Eggspuhler AW, Bauerfeind P, Dorn T, Siegel AM: Wernicke encephalopathy - a severe neurological complication in a clinically inactive Crohn's disease. Eur Neurol 2003;50:184185.

4 Jagadha V, Deck JH, Halliday WC, Smyth HS: Wernicke's encephalopathy in patients on peritoneal dialysis or hemodialysis. Ann Neurol 1987;21:78-84.
5 Grace DM, Alfieri MAH, Leung FY: Alcohol and poor compliance as factors in Wernicke's encephalopathy diagnosed 13 years after gastric bypass. Can J Surg 1998;41:389-392.

-6 Zeyad M, Kerns SC, Shapiro BE: Wernicke encephalopathy. Arch Neurol 2004;61:775.

7 van Noort BA, Bos PJ, Klopping C, Wilmink JM: Optic neuropathy from thiamine deficiency in patient with ulcerative colitis. Doc Ophthalmol 1987;67:45-51.

8 Suzuki S, Kumanomido T, Nagata E, Inoue J, Niikawa O: Optic neuropathy from thiamine deficiency. Int Med 1997;36:532.
9 Haerer AF: DeJong's the Neurologic Examination, ed 5. Philadelphia, JB Lipincott, 1992, pp 420-427.

10 Masdeu JC, Gorelick P: Thalamic astasia: inability to stand after unilateral thalamic lesions. Ann Neurol 1988;23:596-603.

11 Vortmeyer AO, Hagel C, Lass R: Haemorrhagic thiamine deficient encephalopathy following prolonged parenteral nutrition. J Neurol Neurosurg Psychiatry 1992;55:826-829.

12 Weidauer S, Rosler A, Zanella FE, Lanfermann H: Diffusion weighted imaging in Wernicke encephalopathy associated with stomach cancer: case report and review of the literature. Eur Neurol 2004;51:55-57. 